\title{
Dogs in the criminal justice system: Consideration of facility and therapy dogs
}

\author{
Elizabeth Spruin* and Katarina Mozova
}

\section{Abstract}

It is known that the criminal justice process is most often perceived as a negative experience by victims, witnesses, as well as defendants. Whilst measures have been put into place across the globe to improve their experiences, there is still much more which needs to be done, especially as the process can involve secondary victimisation of those participating in it and prolonged trauma. The current opinion piece centres on the use of trained dogs to help the experiences of criminal justice system users during active cases. Whilst this practice is mostly used in North America, hints at bringing varying types of dogs into the criminal justice system are visible elsewhere, too. With the criminal justice users in mind, it is key to establish, from the offset, the positives of such service, but also be very aware of its limitations and challenges, in order for the service delivering what it aims without causing a disruption to the criminal justice process or its users. This piece provides a theoretical and practical analysis of topics surrounding the use of specially trained dogs to support criminal justice system users with the view of highlighting our lack of knowledge on the topic and practical challenges of this service.

\section{HIGHLIGHTS}

- There are important differences between therapy and facility dogs and their utility

Pet Behaviour Science | 2018, Vol.5, 1 - 12

DOI: 10.21071/pbs.v0i5.10084

\section{Elizabeth Spruin* and Katarina Mozova}

Canterbury Christ Church Review
University

\section{* Email:}

liz.spruin@canterbury.ac.uk

UK

Keywords:

criminal justice, facility dog, therapy dog, victim, witness
- Dogs have a place in the Criminal Justice System

- Anecdotal evidence portrays the use of dogs as a beneficial for victims, witnesses and defendants.

- Research surrounding the use of dogs in the legal setting is lacking

\section{INTRODUCTION}

Whilst the role dogs' play in human society has had a long and complex history, the impact that these animals have had on our society is undeniable. Dogs have been shown to enhance human wellbeing, through simple 
pet ownership or active intervention (Friedmann 1995; Fine and Mackintosh 2016). They have been used in a variety of settings (e.g. schools, nursing homes, etc.) and for centuries, dogs have also been utilised within law enforcement where they are specially trained to fulfil a specific role within a variety of areas, from searching for drugs (Lorenzo et al. 2003) and explosives (Gazit and Terkel, 2003), to locating suspects or finding evidence and missing people (Browne, et al. 2006). Only recently, the use of dogs within the Criminal Justice System to specifically help its users' wellbeing (victims, witnesses, defendants) has been explored, originating in the USA through pioneering work of the Courthouse Dogs Foundation, the only not-for-profit organisation advocating for the use of specially trained facility dogs to be utilised to help vulnerable individuals throughout the Criminal Justice System process (Courthouse Dogs Foundation, 2018). This is due to overwhelming evidence highlighting the negative associations criminal justice system users create with their participation (e.g Beckett and Warrington 2015), the need to better care for them so they can provide their best evidence (e.g. O'Mahony, et al. 2016), and the potential of the process re-victimising individuals (i.e. secondary victimisation; e.g. Jordon 2013). Consequently, a multitude of areas for consideration, not necessarily present in other settings, arise, as dogs in this setting are utilised during active cases which is associated with legal challenges. It must be noted that legal systems across the world differ and this piece is not an attempt at highlighting legal issues specific to certain countries; however, some common challenges are considered here which are likely to be visible in a variety of legal systems. Further, academic literature is vastly lacking in certain areas and so other available literature was considered - it was attempted to only utilise unbiased, objective literature (e.g. national regulatory bodies); where this was not possible, information was provided as an example only.

\section{DOG TYPOLOGY: THERAPY AND ASSISTANCE DOGS}

When discussing or researching the effects that dogs can have on human wellbeing, therapy dogs or assistance dogs are utilised (e.g. Berry, et al. 2013); however, differences between these categories are often neglected; an effect of the presence of, or interaction with dogs generally, tend to be considered (e.g. Hoffmann, et al. 2009; Lundqvist, et al. 2017), rather than their effect based on different training and type of intervention. These two categories are vastly different in their behaviours, training, or demeanour and such differences must be appreciated especially when utilising dogs within a legal setting where the ramifications of how dogs are utilised are important. First, brief background relating to these types of needs to be understood. Since the turn of the 20th century, specific dog breeds have been purposefully bred and specially trained as assistance dogs to aid people with disabilities (Fossum 2013). Different breeds of dogs are, historically and contemporarily, associated with different behaviours (such as playfulness, sociability, aggressiveness; Svatberg 2006); further breeding of specific breeds to fit with a job role ensures trainability and predictability of dogs to fulfil a role appropriately (Weiss \& Greenberg 1997; Wilsson and Sundgren 1997). One such role is that of assistance dogs which fall into two broad and distinctive categories: service dogs and facility dogs. Whilst both types of assistance dogs receive extensive training before becoming working dogs, their roles differ. In general, service dogs are trained to do work or perform tasks for people with disabilities, such as visual and hearing impartments, mental illnesses and immobility needs, therefore performing duties such as guiding people who are blind, alerting people who are deaf, pulling a wheelchair, alerting and protecting a person who is having a seizure, or reminding a person with mental illness to take prescribed medications (Camp 2001; Cavalli et al. 2017; Huss 2017). A facility dog is another type of assistance dog that works alongside a professional in a service capacity to assist multiple people with different needs (Tedeschi et al. 2010; Himot, et al. 2017). In this capacity, both the facility dog and working professional are specially trained. Therefore, where a service dog works for one specific person and is trained for their needs, a facility dog works with a professional within an institution and provides services to a variety of individuals. Typical situations in which a facility dog would be utilised would be in educational settings to help facilitate interaction with students, or in healthcare environments to help patients with symptom management (e.g. Bradley and Maldonado 2013; Krause-Parello et al. 2016; Lutwack-Bloom et al. 2008). 
On top of task-oriented benefits, dogs have also been shown to affect human wellbeing in a variety of ways, such as through decreasing anxiety and pain (Barker, et al. 2015), attenuating cortisol and heart rate (Polheber and Matchock 2014), or promoting simple feelings of calmness and happiness (Carew-Lyons 2016). As a result, and due to the wide-ranging possibilities of providing such assistance to people, the use of therapy dogs has been introduced in a number of contexts (e.g. nursing homes, Majic et al. 2013; prisons, Zimmer 2014; or schools and Universities, Barker et al. 2016) to provide affect and comfort to people, showing positive results. Therapy dogs, however, are vastly different to assistance dogs. They are not trained to assist individuals, but rather, they are personal pets. Guidelines as to what criteria a therapy dog needs to fulfil vary across countries. Usually, they are evaluated based only on their temperament (i.e. how a dog reacts in new or unexpected situation) and have to pass a medical exam (Grangen and Kogan 2006). Therapy dogs can undergo further training before being utilised (LaFrance et al. 2007; Obrusnikova et al. 2012); however, for their certification, this is not necessary and it is at the discretion of the institution which aims to include them in their work whether supplementary training is needed (Connor and Miller 2000; Schoenfeld-Tacher et al. 2017). Generally, the selection criteria for therapy dogs to participate in a therapeutic relationship, their level of training or skill set are unsystematic across the world which has implication relating to their possible lack of predictability, sociability or controllability (Cavalli et al. 2017; Grangen and Konan 2006; Mongillo, et al. 2015). Further, it has been found that the guidelines relating to how therapy dogs are certified are open to interpretation and so this assessment is not consistent (Weiss, 2002).

Understanding the general background of these dogs, it should not come unexpectedly that as the important role that dogs play within human society continues to expand, it is crucial that best practice guidelines and standards are not only established, but also strictly adhered to. As each of these types of dogs have a very different training from the other, interchanging the terms and job roles can therefore be detrimental in diluting their value and creating issues of liability and legal issues. Both types of dogs require accreditation from a recognised body (e.g. Assistance Dogs International; Therapy Dogs International) which set national or international standards relating to minimum level of training or skills; though variations in training still exist. Further, not all countries are members of these organisations and so specific regulations relating to these need to be considered by professionals. More specifically, both facility and service dogs are intentionally raised and socialised from early puppyhood in order to effectively support individuals; facility dogs are professionally trained for two years by an internationally recognised Assistance Dog International (ADI) program, which sets strict standards (Cavalli et al. 2017; Tedeschi, et al. 2010). Facility dogs also work with a volunteer or professional who is also trained by an ADI program. The facility dog, as well as the handler, have to be re-assessed regularly by the organisation. These dogs therefore work with a variety of people directly through their trained handler. Both, service and facility dogs, are socialised throughout their training with people of different ages and backgrounds, other animals, and are not reactive to disturbing stimuli (Crenshaw and Stella 2015).

In contrast to assistance dogs, as therapy dogs are personal pets, they have typically undergone basic obedience training with the owner (Connor and Miller 2000; Schoenfeld-Tacher, et al. 2017) and then, in order to be certified by a recognised organisation (e.g. Pets as Therapy, Therapy Dogs International, Delta Society), undergo a temperament assessment which assesses that the dog is sociable and friendly, calm and gentle when being stroked or handled and is not overly fearful of new and unexpected stimuli (Jalongo, et al. 2004; Marcus 2013). However, these dogs do not have to undergo structured training and so their behaviours cannot be as easily predicted (Cavalli et al. 2017; Mongillo, et al. 2015). It must be noted the differences in regulations relating to training of these different types of dogs vary across countries or jurisdictions - it is important for professionals to follow procedures and guidelines in their specific location. 
UTILITY OF DIFFERENT TYPES OF DOGS IN THE CRIMINAL JUSTICE SYSTEM

It is indisputably clear that there are vast differences in training standards and procedures when it comes to the working role that dogs play in our society. As such, although both the level and specificity of a dog's training should be reflected in the type of assistance they provide, there are a growing number of organisations which place dogs within environments for which they might not adequately trained. In particular, the practice of using facility dogs in supporting witnesses throughout the process of a criminal case (also known as 'courthouse facility dog'), has been increasingly adopted across North America. This ranges from courthouse facility dogs joining witnesses for initial forensic interviews, to offering support in actual court settings (Kaiser 2015). These dogs have been used across a number of settings, including vulnerable adult victims (e.g., Ullman 2007) and children of different ages (e.g., Parish-Plass 2008), to help provide support and alleviate stress and anxiety for witnesses when providing evidence and/or testimony (Crenshaw and Stella 2015). The underlying aim of such service is that individuals will be providing best quality evidence, whilst at the same time their levels of discomfort will decrease. Recently however, a growing number of therapy dogs have begun to take similar roles in legal settings, by comforting children throughout the legal process (e.g. Bradley 2014). For example, the American Humane Association published the Therapy Animals Supporting Kids (TASK) manual which encouraged pet therapy teams to assist children in the investigation and prosecution of crimes (Phillips and McQuarrie 2009). However, it seems that in this manual the authors refer to facility dogs that underwent a 'career change' as synonymous to therapy dogs. However, such inference does not adequately highlight the lack of training of therapy dogs and their handlers.

Consequently, placing therapy dogs with witnesses in legal settings, such as courtrooms and interviews, can lead to a number of liability and legal issues, as unlike facility dogs, these dogs (and handlers) might not be adequately trained within these settings and the predictability of therapy dogs, even with training, is questionable. For instance, many therapy dog organizations do not require that a dog present for evaluation to have any obedience or training classes (Connor and Miller 2000; Schoenfeld-Tacher et al. 2017). This can have repercussions both for the people the therapy dog comes in contact with, but also for the welfare of the therapy dog. Zamir (2006) stated that the use of therapy dogs in any setting requires the animal to be treated as participants in a mutually beneficial relationship and that the needs of the animal must always be considered, accommodated and balanced with the needs of the client. As such, if the therapy dog shows signs of stress while a witness is testifying, the therapy dog must be removed immediately (Mongillo et al. 2015), this can have clear consequences to the court proceedings and the welfare of the witness.

With that, there are differences in working patterns between therapy and facility dogs. There are no clear guidelines relating to how long a therapy dog should work (Mongillo et al. 2015). Previous research in the area usually utilised this type of dog for short periods of time without causing distress (60 minutes maximum; e.g. Glenk et al. 2014; 20 minutes - Palestrini et al. 2017) and the expectation is that a therapy dog should only be expected to tolerate physical intimacy with those unknown to them for minutes (Glenk, 2017). The Animal Assisted Intervention International (the only organisation aiming to facilitate global standards surrounding animal assisted intervention; Couling, 2015) suggests that dogs which are not specially trained for a specific purpose (as facility dogs are) should not work more than one hour at any one time, followed by at least a half hour break. Generally, there are no set guidelines as to how long a therapy dog can work for; however, it they have to be removed from a situation upon showing any signs of distress and often need to take breaks frequently (Haubenhofer and Kirchengast 2007; Marcus 2011). This creates major issues as it is unlikely a therapy dog will be able to support an individual throughout the whole interview/testimony and may impact upon the legal process. It is impossible to provide an accurate account of how long a police interview or a court testimony lasts, as this varies depending on age or special needs of an individual, offence in question, and more (e.g. Memon, et al. 2010; Wilson and Powell 2012). Whilst the interview itself might only last for a short time, there might be frequent breaks, a waiting period, and an introduction period of 
the dog to the individual. The welfare of facility dogs is equally as important; however, they have been professionally trained work full working days and provide quiet companionship to vulnerable individuals in the legal setting (Crenshaw and Stella 2015). Through their training, they enjoy being petted and enjoy resting quietly (Crenshaw and Stella 2015). These dogs have further been specially bred and chosen because of their calm demeanour and ability to work in high stress environments (Timmins and Fine 2006; Weiss and Greenberg 1997; Wilsson and Sundgren 1997), thereby decreasing the risk of creating legal issues.

Further to the wellbeing of the dog, only facility dogs are appropriately socialised and tested (Baun et al. 2006; Sachs-Ericsson and Merbitz, 2002). Organisations responsible for certifying therapy dogs do not require contact with children during their evaluation process, rather, the evaluation focuses on and measures different aspects of the dog's temperament (e.g., stability, shyness, aggressiveness, friendliness), and does not test dogs for safe physical contact with children; this puts children at risk for dog bites, becoming uncomfortable, and the dog becoming distressed (Turner, 2006). Another concern is that pet therapy organisations require that the dog's handler always be attached to the dog by a leash (LaFrance et al. 2007). This would mean that the handler must be in attendance for all private or legally sensitive matters with witnesses (e.g., forensic interviews, medical exams, therapy sessions, defence interviews, testifying). This would potentially impact on the quality of evidence gained, which is against the legal and moral objectives of acquiring evidence (e.g. Cooke and Davies, 2001; Gordon and Fleischer 2010; Phillips 2015 Powell, et al. 2010; Sandoval 2010). Further, it is questionable what the presence of the handler means in regard to the handler potentially becoming a witness to the case or being required to testify about the interview they were a part of.

Another issue, relevant to the use of therapy dogs in the Criminal Justice System, is the training of the dog handler. There is no standardised vetting or screening of handlers, rather, handlers simply need to be of 'good character' (not further defined) and are only trained if they choose to - often through basic obedience training they underwent with their dog (Tedeschi et al. 2010). There is no screening or criminal background check carried out for handlers, which can have detrimental ramifications when working in the legal system - to the authors' knowledge, this is something not considered in literature. It then becomes the responsibility of a specific agency to undergo such screening which can further complicate the process. In contrast, each courthouse facility dog also has a professionally trained handler working in the legal field (e.g., victim advocate, forensic interviewer, detectives, lawyer, etc), who are also carefully vetted and selected to receive one of their highly trained canines (Marquad 2017). Similarly to handling therapy dogs, regular re-certification of the $\mathrm{dog} /$ handler team is necessary.

Table 1. Training standards: Therapy vs Facility dogs

\begin{tabular}{cll}
\hline Therapy dog & & \\
\hline $\begin{array}{r}\text { Type of } \\
\text { training }\end{array}$ & $\begin{array}{c}\text { Likely } \\
\text { behaviour }\end{array}$ & \multicolumn{1}{c}{ Recommendation } \\
\hline $\begin{array}{l}\text { No standard } \\
\text { training }\end{array}$ & $\begin{array}{l}\text { Non } \\
\text { predictable }\end{array}$ & $\begin{array}{l}\text { - Undergo appropriate } \\
\text { training } \\
\text { - Increase their } \\
\text { socialization } \\
\text { (individuals of } \\
\text { different backgrounds, } \\
\text { or ages) }\end{array}$ \\
& \\
&
\end{tabular}

Facility dog

\begin{tabular}{|c|c|c|}
\hline $\begin{array}{l}\text { Type of } \\
\text { training }\end{array}$ & $\begin{array}{c}\text { Likely } \\
\text { behaviour }\end{array}$ & Recommendation \\
\hline $\begin{array}{l}\text { - Standard } \\
\text { training }(>2 \\
\text { years) } \\
\text { - Early } \\
\text { socialisation } \\
\text { - Purposeful } \\
\text { breeding }\end{array}$ & $\begin{array}{l}\text { Highly } \\
\text { predictable }\end{array}$ & $\begin{array}{l}\text { Facility dogs can be } \\
\text { utilised within the } \\
\text { Criminal Justice } \\
\text { System }\end{array}$ \\
\hline
\end{tabular}

On top of issues surrounding training, certification, or handlers, there are possible challenges to consider simply due to a dog being present. One possible issue with having a dog present during interview or testimony is that the dog is used as a 'reward' and as such can invoke a false confession (Lassiter and 
Meissner 2010). Whilst all interviewers are aware that the dog should not be used as such, because of the temperament and training of facility dogs, these will simply lay down by the individual and so no prompting is necessary for the dog to engage with an individual. As such, the dog serves more like a 'comfort item' (normally an object used to provide psychological comfort), or a 'communication aid' (normally an object or service used to aid individuals communicate better) special measures commonly accepted in many legal systems (e.g. Cross and Whitcomb 2017; Hamlyn, et al. 2004). However, therapy dogs are not necessarily trained to this extent and might not engage with an individual as needed (e.g. resting beside an individual for a prolonged time period), without compromising their welfare (Glenk 2017). Alternatively, the authors put forward the argument that the handler might misunderstand or overstep their role and say something inappropriate, potentially portraying the dog as a reward.

This leads to another issue for consideration: disruption. As stated before, criminal justice systems operate on the premise of seeking the truth and so aim to achieve best available evidence (Gordon and Fleischer 2010; Powell et al. 2010; Sandoval 2010). A therapy dog which is not trained to simply laydown and might become bored, distressed, or walk around, will likely affect the quality of evidence (disturb or distress the individual), or might potentially cause an interview/testimony to be stopped (Mongillo et al. 2015; Zamir 2006). As stated before, therapy dogs are not socialised and trained to the same standards as facility dogs and so there is a higher likelihood that a therapy dog will become distressed and so removed (Baun et al. 2006; Cavalli et al. 2017; Turner 2006). Lastly, there is the argument that simply having a dog present during a police interview (which might be shown as evidence in front of a jury) or during trial will automatically evoke sympathy in the jury (Grimm 2013). Whilst studies have shown that jurors do hold opinions about those testifying (e.g. Cohen 2013), a mock juror study showed that an appropriately trained facility dog (when compared to a teddy bear or no intervention) had no effect on the jurors' perceptions of witness credibility (Burd, 2013). Further exploration is needed into how the presence of a facility dog, or a therapy dog, might impact on jury/judge perceptions.
However, based on available literature, the authors suggest that as facility dogs are allowed to be quietly placed into a witness box without a handler, they would not be perceived as a disruption, as compared to, therapy dogs, as they might exude more personality, move around, and similar.

Table 2. Handler training: Therapy vs Facility dogs

\begin{tabular}{|c|c|c|}
\hline \multicolumn{3}{|l|}{ Therapy dog } \\
\hline $\begin{array}{l}\text { Training / } \\
\text { selection of the } \\
\text { handler }\end{array}$ & Dilemma & $\begin{array}{l}\text { Recommendation } \\
\text { or Comments }\end{array}$ \\
\hline No training & $\begin{array}{l}\text { - Possibility of } \\
\text { not acting }\end{array}$ & $\begin{array}{l}\text { - Appropriate vetted } \\
\text { and screened }\end{array}$ \\
\hline $\begin{array}{l}\text { No } \\
\text { standardised } \\
\text { vetting or } \\
\text { screening }\end{array}$ & $\begin{array}{l}\text { appropriately } \\
\text { in a legal } \\
\text { situation } \\
\text { - Have } \\
\text { unsuitable } \\
\text { background } \\
\text { history }\end{array}$ & $\begin{array}{l}\text { - Specific training to } \\
\text { such institution }\end{array}$ \\
\hline
\end{tabular}

\begin{tabular}{|c|c|c|}
\hline \multicolumn{3}{|l|}{ Facility dog } \\
\hline $\begin{array}{l}\text { Training / } \\
\text { selection of the } \\
\text { handler }\end{array}$ & Dilemma & $\begin{array}{l}\text { Recommendation } \\
\text { or Comments }\end{array}$ \\
\hline $\begin{array}{l}\text { - Trained } \\
\text { - Vetted and } \\
\text { screened } \\
\text { - Legal } \\
\text { professional }\end{array}$ & & $\begin{array}{l}\text { Trained handlers or } \\
\text { trained legal } \\
\text { professionals } \\
\text { understand the } \\
\text { Criminal Justice } \\
\text { System } \\
\text { environment }\end{array}$ \\
\hline
\end{tabular}




\section{CONCLUSIONS AND RECOMMENDATIONS}

Overall, whilst there is a very valid argument to introducing dogs, generally, into the Criminal Justice System processes, the differences between therapy and facility dogs need to be appreciated and so they need to be used in specific settings. Following the literature discussed herein, we suggest a number of considerations for good practice when using these two different categories of dogs (Tables 1, 2, 3 \& 4).

\section{Therapy dog}

\section{Guidelines}

- No guidelines

- They likely work short hours with frequent breaks

- Not trained to be utilised in an emotionally charged environment

\section{Dilemma}

- Handler attached to the dog via a leash

- Dog removed if showing signs of distress

- Likely not be able to support an individual during the whole of a police interview/court testimony

\section{Recommendation / Comments}

- Therapy dogs should not be expected to fulfil a position of a working dog.

- Their presence can be very useful in specific settings only - where they are not expected to fulfill a certain role (e.g. remain next to one person for a prolonged time period).

Table 3. Therapy dog guidelines and recommendations

\section{Facility dog}

\section{Guidelines}

- Trained to lay still

- Trained to not be effected by stressful environments

\section{Dilemma}

Dogs can accompany an individual without the handler having to hold the dog's leash

\section{Recommendation / Comments}

These dogs are able to support individuals for prolonged periods of time. Therefore, they are suitable for all setting within the Criminal Justice System process.

Table 4. Facility dog guidelines and recommendations

We advise that therapy dogs could be introduced into some aspects of the legal process but only following a thorough selection process; they should never be allowed to enter a police interview, or a courtroom. Facility dogs, however, can be utilised throughout the whole of the process, including being present during forensic/police interviewing, medical examinations, or whilst giving testimony. Whilst best practice guidelines have been developed for these types of dogs separately, these guidelines have little empirical evidence behind them which calls for a need to establish an evidence base. We believe that criminal justice system users can benefit from utilising specially trained dogs in supporting them and the little available evidence is supportive of this. However, introducing such service needs to be well thought out and planned in order to truly make the criminal justice journey better for its users. 


\section{REFERENCES}

Barker, S.B., Barker, R.T., McCain, N.L. and Schubert, C.M. 2016. A randomized cross-over exploratory study of the effect of visiting therapy dogs on college student stress before final exams. A Multidisciplinary Tournal of the Interactions of People and Animals 29(1): 35-46.

Barker, S.B., Knisely, I.S., Schubert, C.M., Green, J.D. and Ameringer, S. 2015. The effect of an animal-assisted intervention on anxiety and pain in hospitalized children. $A$ Multidisciplinary Journal of the Interactions of People and Animals, 28 (1), 101-112.

Baun, M., Johnson, R. and McCabe, B. 2006. Human-Animal Interaction and Successful Aging. In Handbook on Animal Assisted Therapy, 287-302, ed. A.H. Fine. USA: Elsevier.

Beckett, H., Warrington, C. 2015 Making iustice work: experiences of criminal iustice for children and young people affected by sexual exploitation as victims and witnesses. University of Bedfordshire

Berry, A., Borgi, M., Francia, N., Alleva, E. and Cirulli, F. 2013. Use of assistance and therapy dogs for children with autism spectrum disorders: A critical review of the current evidence. The journal of alternative and complementary medicine, 19(2): 73-80.

Bradley, P. 2014. Therapy dogs in the courtroom as advocates for child witnesses: An interpretive phenomenological analysis of iudges' opinions, experiences, and rulings. Ph.D. thesis, Texas A\&M University-Commerce.

Bradley, I. and Maldonado, N. 2013. Effects of a facility dog on student learning and learning environment. Paper presented at the Annual Meeting of the Mid South Educational Research Association.
Browne, C, Stafford, K, and Fordham, R (2006) The use of scent-detection dogs. Irish Veterinary Journal, 59, 97 - 104.

Burd, K. 2013. The effects of facility animals in the courtroom on iuror decision-making. Master's thesis, Arizona State University.

Camp, M.M., 2001. The use of service dogs as an adaptive strategy: A qualitative study. American Tournal of Occupational Therapy, 55(5), pp.509-517.

Cavalli, C.M., Carballo, F., Dzik, M.V., Underwood, S. and Bentosela, M. 2017. Are animal-assisted activity dogs different from pet dogs? A comparison of their sociocognitive abilities. Journal of Veterinary Behavior, 23, 76-81.

Cohen, C.R., 2013. Demeanor, Deception and Credibility in Witnesses. ABA Section of Litigation Section, 3, 23-35.

Carew-Lyons, A. 2016. Impact of dog visitation on a hospitalized child's mood. Ph.D. thesis, University of Massachusetts Boston.

Cooke, P. and Davies, G. 2001. Achieving best evidence from witnesses with learning disabilities: new guidance. British Journal of Learning Disabilities, 29(3), 84-87.

Connor, K. and Miller, I., 2000. Animalassisted therapy: an in-depth look. Dimensions of Critical Care Nursing, 19(3): 20-26.

Couling, K., 2017. Facilitating an animalassisted intervention program: the risks and rewards of working with animals in helping and educational settings. Master's Thesis. University of Alberta.

Courthouse Dogs Foundation (2018). Home. Available at: https://courthousedogs.org/ (Accessed 15 February 2018). 
Crenshaw, D. A. and Stella, L. 2015. Court testimony: animal-assisted trauma-informed play therapy to help traumatized child and adolescent witnesses. In Play Therapy with Children and Adolescents in Crisis, 334-351, ed. N.B. Webb. London: The Guildford Press.

Cross, T.P. and Whitcomb, D. 2017. The practice of prosecuting child maltreatment: Results of an online survey of prosecutors. Child abuse \& neglect, 69, 20-28.

Fine, A.H. and Mackintosh, T.K. 2016. Animalassisted interventions: Entering a crossroads of explaining an instinctive bond under the scrutiny of scientific inquiry. In Encyclopaedia of mental health, 68-73, ed. H. S. Friedman. Oxford: Elsevier.

Fossum, J. 2013. The history of services dogs: How do they work? Presented at the National Centre for Victims of Crime National Conference, Phoenix, AZ.

Friedmann, E. 1995. The role of pets in enhancing human well-being: Physiological effects. In Human-animal interaction: Benefits and responsibilities of pet ownership, 33-54, ed. I. Robinson. Oxford: Elsevier.

Gazit, I., and Terkel, J. 2003. Explosives detection by sniffer dogs following strenuous physical activity. Applied Animal Behaviour Science, 81: 149-161.

Glenk, L.M. 2017. Current perspectives on therapy dog welfare in animal-assisted interventions. Animals, 7(2),7-24.

Glenk, L. M., Kothgassner, O. D., Stetina, B. U., Palme, R., Kepplinger, B. and Baran, H. 2014. Salivary cortisol and behavior in therapy dogs during animal-assisted interventions: A pilot study. Journal of Veterinary Behavior: Clinical Applications and Research, 9(3), 98-106.
Gordon, N.J. and Fleisher, W.L. 2010. Effective interviewing and interrogation techniques. London: Academic Press.

Granger, B. and Kogan, L. 2006. Characteristics of Animal-Assisted Therapy/Activity in Specialized Settings. In Handbook on Animal Assisted Therapy, 263-286, ed. A.H. Fine. USA: Elsevier.

Grimm, A. 2013. An examination of why permitting therapy dogs to assist childvictims when testifying during criminal trials should not be permitted. J. Gender Race $\mathcal{E}$ Just., 16: 263-292.

Hamlyn, B., Phelps, A., Turtle, I. and Sattar, G. 2004. A re special measures working? Evidence from surveys of vulnerable and intimidated witnesses. Home Office Research, Development and Statistics Directorate. London: Home Office.

Haubenhofer, D.K. and Kirchengast, S. 2007. 'Dog Handlers' and Dogs' Emotional and Cortisol Secretion Responses Associated with Animal-Assisted Therapy Sessions. Society $\mathcal{E}$ Animals, 15(2): 127-150.

Himot, L., Gordon, T., Harrison, R. L. and de Chesnay, M. 2017. Canine partners in health care. In Nursing Research Using Case Studies: Qualitative Designs and Methods in Nursing, 145-154, ed. M. De Chaney. New York: Springer Publishing.

Hoffmann, A.O., Lee, A.H., Wertenauer, F., Ricken, R., Jansen, J.J., Gallinat, J. and Lang, U.E. 2009. Dog-assisted intervention significantly reduces anxiety in hospitalized patients with major depression. European Journal of Integrative Medicine, 1(3): 145-148.

Huss, R.J. 2017. Legal and policy issues for animal assisted interventions with special populations. Applied Developmental Science, 21(3): 217-222. 
Jalongo, M.R., Astorino, T. and Bomboy, N. 2004. Canine visitors: The influence of therapy dogs on young children's learning and wellbeing in classrooms and hospitals. Early Childhood Education Journal, 32(1): 9-16.

Jordon. J. 2013. From Victim to Survivor - and from Survivor to Victim: Reconceptualising the Survivor Journey. Sexual Abuse in Australia and New Zealand. 5(2): 48-56

Kaiser, M. 2015. Sit, stay, now beg for me: A look at the courthouse dogs program and the legal standard Pennsylvania should use to determine whether a dog can accompany a child on the witness stand. Villanova Law Review, 60: 343-382.

Krause-Parello, C.A., Levy, C., Holman, E. and Kolassa, J.E. 2018. Effects of VA Facility Dog on Hospitalized Veterans Seen by a Palliative Care Psychologist: An Innovative Approach to Impacting Stress Indicators. American Iournal of Hospice and Palliative Medicine ${ }^{\circledR}, 35(1)$ : 5-14.

LaFrance, C., Garcia, L.J. and Labreche, I. 2007. The effect of a therapy dog on the communication skills of an adult with aphasia. Iournal of communication disorders, 40(3):.215-224.

Lassiter, G. D. and Meissner, C. A. 2010. Police interrogations and false confession: Current research, practice, and policy recommendations. USA: American Psychological Association.

Lorenzo, N., Wan, T. L., Harper, R. J., Hsu, Y.L., Chow, M., Rose, S. and Furton, K.G. 2003. Laboratory and field experiments used to identify Canis lupus var. familiaris active odor signature chemicals from drugs, explosives, and humans. Analytical and Bioanalytical Chemistry, 376: 1212-1224.
Lundqvist, M., Carlsson, P., Siödahl, R., Theodorsson, E. and Levin, L.A. 2017. Patient benefit of dog-assisted interventions in health care: a systematic review. BMC complementary and alternative medicine, 17(1): 358-369.

Lutwack-Bloom, P., Wijewickrama, R. and Smith, B. 2005. Effects of pets versus people visits with nursing home residents. Tournal of Gerontological Social Work, 44(3-4): 137-159.

Majić, T., Gutzmann H., Heinz A., Lang, U.E. and Rapp, M.A. 2013. Animal-assisted therapy and agitation and depression in nursing home residents with dementia: a matched case-control trial. The American Journal of Geriatric Psychiatry, 21(11): 10521059.

Marcus, D.A. 2011. The power of wagging tails: a doctor's guide to dog therapy and healing. New York: Demos Medical Publishing.

Marcus, D.A. 2013. The science behind animal-assisted therapy. Current pain and headache reports, 17(4): 322.

Marquard, M., 2017. Puppy Prescriptions: Perceptions of Facility Dogs and Their Contribution to Psychosocial Care in Pediatric Hospitals. Ph.D. thesis, Mills College.

Memon, A., Meissner, C. A., and Fraser, J. 2010. The Cognitive Interview: A metaanalytic review and study space analysis of the past 25 years. Psychology, Public Policy, and Law, 16(4), 340-372.

Mongillo, P., Pitteri, E., Adamelli, S., Bonichini, S., Farina, L. and Marinelli, L. 2015. Validation of a selection protocol of dogs involved in animal - assisted intervention. Journal of Veterinary Behavior: Clinical Applications and Research, 10(2), 103-110. 
Obrusnikova, I., Bibik, I.M., Cavalier, A.R. and Manley, K. 2012. Integrating therapy dog teams in a physical activity program for children with autism spectrum disorders. Journal of Physical Education, Recreation $\mathcal{E}$ Dance, 83(6): 37-48.

O'Mahony, B., Creaton, J., Smith, K., Milne, R. 2016. Developing a professional identity in a new work environment: the views of defendant intermediaries working in the criminal courts. Journal of Forensic Practice, 18(2): 155-166.

Palestrini, C., Calcaterra, V., Cannas, S., Talamonti, Z., Papotti, F., Buttram, D. and Pelizzo, G. 2017. Stress level evaluation in a dog during animal-assisted therapy in pediatric surgery. Tournal of Veterinary Behavior: Clinical Applications and Research, 17, 44-49.

Parish-Plass, N. 2008. Animal-assisted therapy with children suffering from insecure attachment due to abuse and neglect: A method to lower the risk of intergenerational transmission of abuse? Clinical Child Psychology and Psychiatry, 13: 7-30.

Phillips, A. 2015. The Human-Animal Relationship in Context of the Juvenile and Criminal Justice Systems. In Handbook on Animal Assisted Therapy, 295-303, ed. A.H. Fine. USA: Elsevier.

Phillips, J. D. and McQuarrie, D. 2010. Therapy Animals Supporting Kids (TASK) manual. American Humane Association.

Polheber, J. P. and Matchock, R. L. 2014. The presence of a dog attenuates cortisol and heart rate in the trier social stress test compared to human friends. Journal of Behavioural Medicine, 37(5): 860-867.
Powell, M.B., Wright, R. and Clark, S. 2010. Improving the competency of police officers in conducting investigative interviews with children.Police practice and research: an international journal, 11(3): 211-226.

Sachs-Ericsson, N., Hansen, N.K. and Fitzgerald, S. 2002. Benefits of assistance dogs: A review. Rehabilitation Psychology, 47(3), 251277.

Sandoval, G.N. 2010. Court Facility DogsEasing the Apprehensive Witness. The Colorado Lawyer, 39(17): 17-23.

Schoenfeld-Tacher, R., Hellyer, P., Cheung, L. and Kogan, L. 2017. Public Perceptions of Service Dogs, Emotional Support Dogs, and Therapy Dogs. International journal of environmental research and public health, 14(6), 642-674.

Svatberg, K. 2006. Breed-typical behaviour in dogs-historical remnants or recent constructs? Applied Animal Behaviour Science, 96(3): 293-313.

Tedeschi, P., Fine, A. H. and Helgeson, I. I. 2010. Assistance animals: their evolving role in psychiatric service applications. In Handbook on Animal Assisted Therapy, 421-440, ed. A.H. Fine. USA: Elsevier.

Timmins, R. and Fine, A. H. 2006. Role of the Veterinary Family Practitioner in AnimalAssisted Therapy and Animal-Assisted Activity Programs. In Handbook on Animal Assisted Therapy, 475-486, ed. A.H. Fine. USA: Elsevier.

Turner, D. C. 2006. The Future of Research, Education, and Clinical Practice in the AnimaHuman Bond and Animal-Assisted Therapy. Part A: The Role of Ethology in the Field of Human-Animal Relations and Animal Assisted Therapy. In Handbook on Animal Assisted Therapy, 487-498, ed. A.H. Fine. USA: Elsevier. 
Ullman, S. 2007. Relationship to perpetrator, disclosure, social reactions, and PTSD symptoms in child sexual abuse survivors. Journal of child sexual abuse, 16: 19-36.

Weiss, E. 2002. Selecting shelter dogs for service dog training. Tournal of Applied Animal Welfare Science, 5(1), 43-62.

Weiss, E. and Greenberg, G. 1997. Service dog selection tests: effectiveness for dogs from animal shelters. Applied Animal Behaviour Science, 53(4), 297-308.

Wilson, C. and Powell, M. 2012. A quide to interviewing children: Essential skills for counsellors, police lawyers and social workers. Oxon: Routledge.
Wilsson, E. and Sundgren, P.E. 1997. The use of a behaviour test for the selection of dogs for service and breeding, I: Method of testing and evaluating test results in the adult dog, demands on different kinds of service dogs, sex and breed differences. Applied Animal Behaviour Science, 53(4): 279-295.

Zamir, T. 2006. The moral basis of animalassisted therapy. Society $\mathcal{E}$ Animals, 14(2), 179199.

Zimmer, R. M. 2014. Partnering shelter dogs with prison inmates: An alternative strategy to reduce recidivism and teach social therapy (2014). Master's Thesis. American Public University. 